\title{
Aislamiento e identificación de diez cepas bacterianas desnitrificantes a partir de un suelo agrícola contaminado con abonos nitrogenados proveniente de una finca productora de cebolla en la Laguna de Tota, Boyacá, Colombia
}

\author{
Joaquín L. Benavides López de Mesa¹, Gladys M. Quintero', \\ Olga Lucía Ostos Ortiz² \\ ${ }^{1}$ Universidad de La Salle, ${ }^{2}$ Universidad Colegio Mayor de Cundinamarca \\ Correspondencia: jbenavides@lasalle.edu.co
}

Recibido: 13-10-06 / Aceptado: 17-11-06

\begin{abstract}
Resumen
Este articulo presenta los resultados de la versatilidad adaptativa y tolerancia de una consorcio bacteriano constituido por 10 cepas bacterianas endémicas de un suelo agrícola contaminado, proveniente de una finca productora de cebolla ubicada en la laguna de Tota en Aquitania, Boyacá, Colombia, expuesto al uso incontrolado de fertilizantes nitrogenados. La consorcio bacteriano aislado del suelo está conformado por: Bacillus megaterium, Bacillus licheniformis, Pseudomonas stutzeri, Acinetobacter sp, Propionibacterium sp, Peptoestreptococcus sp, Sthaphylococcus coagulasa negativa, Corynebacterium sp, Clostridium sp y Actinomyces sp. Se demostró que los microorganismos aislados tienen capacidad desnitrificante in vitro, transformando el nitrato a nitrógeno molecular. La consorcio bacteriano aislado se constituye en una alternativa de biorremediación para recuperar suelo agrícola contaminado con exceso de fertilizantes nitrogenados.

Palabras Claves: agentes fertilizantes, amonio, biorremediación, desnitrificación, nitratos, urea.

Abstract

This article presents the results of the adaptative versatility and tolerance of a bacterial consortium made up of 10 bacterial stocks endemic to a contaminated soil coming from an onion farm located near Laguna de Tota, Aquitania, Boyacá, Colombia. This soil has been exposed to the uncontrolled use of nitrogen rich fertilizers. The bacterial consortium from the soil is made up of Bacillus megaterium, Bacillus licheniformis, Pseudomonas stutzeri, Acinetobacter sp, Propionibacterium sp, Peptoestreptococcus sp, coagulasa negative sthaphylococci, Corynebacterium sp, Clostridium sp, and Actinomyces sp. It was demonstrated that the isolated microorganisms have in vitro denitrifying capabilities, thus transforming nitrates to molecular nitrogen. The isolated bacterial association constitutes a bioremediation alternative to recover the soil that has been contaminated by the excess of nitrogen rich fertilizers.
\end{abstract}

Key words: ammonium, biodegradation, denitrification, fertility agents, nitrates, urea. 


\section{Introducción}

La salinización de suelos es un problema universal y complejo que ocasiona un impacto ambiental negativo, el cual se ha incrementado con el pasar de los años como consecuencia del uso indiscriminado de abonos, convirtiéndose en una amenaza para la agricultura, la flora y fauna autóctona (1).

Las técnicas de biorremediación, constituyen una importante alternativa de solución a la salinización de suelos, ya que permiten eliminar o inmovilizar contaminantes, transformándolos o degradándolos a sustancias menos peligrosas o inocuas. Dichas técnicas utilizan microorganismos con capacidad para utilizar los contaminantes como fuente de energía o como aceptores y donadores de electrones dentro de la cadena respiratoria, mejorando así, la calidad y condiciones físico-químicas del suelo, contribuyendo en el crecimiento, rendimiento y calidad de las cosechas (2).

De esta forma, la biorremediación de suelos contaminados por fertilizantes nitrogenados (gallinaza, urea), puede realizarse mediante la aplicación y/o bioaumentación de microorganismos desnitrificantes autóctonos, que utilizan formas de nitrógeno inorgánico o amonio previamente reducido convirtiéndolo en sustancias gaseosas como $\mathrm{N}_{2} \mathrm{O}$, $\mathrm{NO}$ y $\mathrm{N}_{2}$, los cuales son emitidos a la atmósfera (3).

Las bacterias desnitrificantes son filogenéticamente diversas y están distribuidas ampliamente en ecosistemas acuáticos y terrestres. El proceso de desnitrificación ocurre en muchas especies de Eubacterias y en unas pocas Arqueobacterias. Las Proteobacterias, las Enterobacterias, son anaerobios facultativos, debido a que cambian el aceptor de electrones como el oxigeno por óxidos de nitrógeno bajo condiciones anóxicas. Otros estudios han demostrado que las bacterias desnitrificantes y fijadoras de nitrógeno se encuentran en la capa superficial del suelo a una profundidad de $5 \mathrm{~cm}$ (4).

El aislamiento de estos microorganismos se realizó en un medio de cultivo al que se le añadió nitrato potásico como aceptor de electrones, una fuente de carbono no fermentable como donador de electrones y sales minerales a fin de no seleccionar organismos fermentativos.

El objetivo del estudio, fue aislar e identificar mediante el uso de medios selectivos y pruebas bioquímicas convencionales, consorcios bacterianos desnitrificantes a partir de un suelo proveniente de una finca productora de cebolla cerca a la laguna de Tota (Boyacá) contaminado por exceso de fertilizantes (nitratos y amonio).

\section{Materiales y métodos}

\section{Toma de muestra de suelo}

La muestra de suelo fue traída de la finca Siempre Viva la cual se encuentra ubicada en el municipio de Aquitania (Boyacá). Para la recolección del suelo se delimitó un área aproximada de $1500 \mathrm{~m}^{2}$ dentro de la cual se tomaron muestras compuestas utilizando un muestreo aleatorio en zig-zag. Se removió la capa superficial presente y se excavó hasta una profundidad de $20 \mathrm{~cm}$. Las muestras fueron empacadas en 14 sacos (40 kilos). La selección de la muestra se basó en análisis físico-químicos previos confirmando altas concentraciones de nitratos.

\section{Montaje ex situ}

La muestra fue trasladada a un invernadero construido en la Sede La Floresta de la Universidad de La Salle, donde se utilizó un área total de terreno de $14 \mathrm{~m}^{2}$, de los cuales $6 \mathrm{~m}^{2}$ se emplearon para la disposición del suelo. Se realizó el montaje de 3 surcos problema (unidades experimentales) y un control, cada surco de $52 \mathrm{~cm}$ de ancho, por 1,30 $\mathrm{cm}$ de largo, por $20 \mathrm{~cm}$ de profundidad; cada unidad experimental poseía tres réplicas, el montaje contó con un sistema de impermeabilización para la recolección y manejo de lixiviados con el fin de evitar la contaminación del suelo problema, suelos aledaños y acuíferos.

\section{Homogenizado de suelo}

De cada muestra de suelo secado y tamizado se pesaron $25 \mathrm{~g}$. y se homogenizaron en $225 \mathrm{ml}$ agua peptonada $(0,85 \%)$, con cicloheximida $(50 \mathrm{mg} / \mathrm{ml})$ para inhibir el 
crecimiento fúngico; se mantuvieron en agitación a $120 \mathrm{rpm}$, por 30 minutos a temperatura ambiente $\left(20^{\circ} \mathrm{C}\right)$.

\section{Conteo preliminar de células viables}

A partir del homogenizado se determinó la concentración inicial de bacterias viables heterótrofas y desnitrificantes de cada uno de los surcos mediante la técnica de recuento por vertido en placa, previa preparación de la muestra de suelo por homogenización y secado, según protocolo.

\section{Recuento de desnitrificantes}

A partir del homogenizado se prepararon diluciones seriadas en base 10 en medio líquido mineral; $\left(10^{0}\right.$ a $\left.10^{-7}\right)$; de cada dilución se inoculó, por triplicado, $0,1 \mathrm{ml}$ a placas de petri. Luego se agregaron $20 \mathrm{ml}$ de medio agar mineral mínimo fundido y mantenido a $45^{\circ} \mathrm{C}$. Una vez solidificados los medios se llevaron a incubar a $37^{\circ} \mathrm{C}$ durante 48-96 horas, para obtener crecimiento de colonias. Para cuantificar las colonias se seleccionaron las diluciones que presentaron crecimiento entre 30 y 300 UFC, se realizó el cálculo teniendo en cuenta el título de la dilución y la cantidad de inóculo utilizado. Los resultados se expresan en UFC/g de suelo.

\section{Aislamiento e identificación de consorcios denitrificantes bacterianos nativos}

A partir del crecimiento obtenido en las placas de recuento de desnitrificantes y heterótrofos se realizó el aislamiento de los consorcios bacterianos nativos mediante resiembra en medio de sales minerales. Los cultivos se manipularon en iguales condiciones de crecimiento a las descritas para los recuentos bacterianos y se realizaron las resiembras necesarias en medio sólido hasta obtener cepas puras. Las cepas puras componentes de los consorcios nativos se resembraron en medios de cultivo de aislamiento primario básicos y con el fin de obtener el crecimiento suficiente para su completa identificación y para mantenerlas viables.

Los microorganismos aislados se determinaron según los protocolos convencionales de identificación: teniendo en cuenta las características macroscópicas de las colonias, la morfología microscópica, por medio de la tinción de Gram y coloraciones especiales para cápsula, esporas e inclusiones citoplasmáticas. Según las características micro y macroscópicas de las colonias aisladas se procedió a la aplicación de los protocolos convencionales y pruebas bioquímicas especiales para la identificación de bacterias provenientes de suelo.

\section{Resultados}

Recuento Inicial de células viables: $1.3 \times 10^{4} \mathrm{UFC} / \mathrm{g}$. de suelo. Una vez se observó crecimiento a partir de los aislamientos positivos se procedió a realizar caracterización macro y microscópica de las colonias aisladas. El recuento promedio de UFC/g de suelo post-tratamiento fue de $6.3 \times 10^{4}$, el recuento promedio en el surco control fue de $2,6 \times 10^{4}$.

Identificación bioquímica. En la Tabla 1 se presentan los microorganismos aislados e identificados mediante pruebas bioquímicas.

\section{Microorganismos identificados}

Bacillus megaterium

Bacillus licheniformis

Pseudomonas stutzeri

Acinetobacter $s p$

Propionibacterium $s p$

Peptoestreptococcus sp

Sthaphylococcus coagulasa negativa

Corynebacterium sp

Clostridium sp

Actinomyces sp

Tabla 1. Microorganismos aislados e identificados mediante pruebas bioquímicas. 


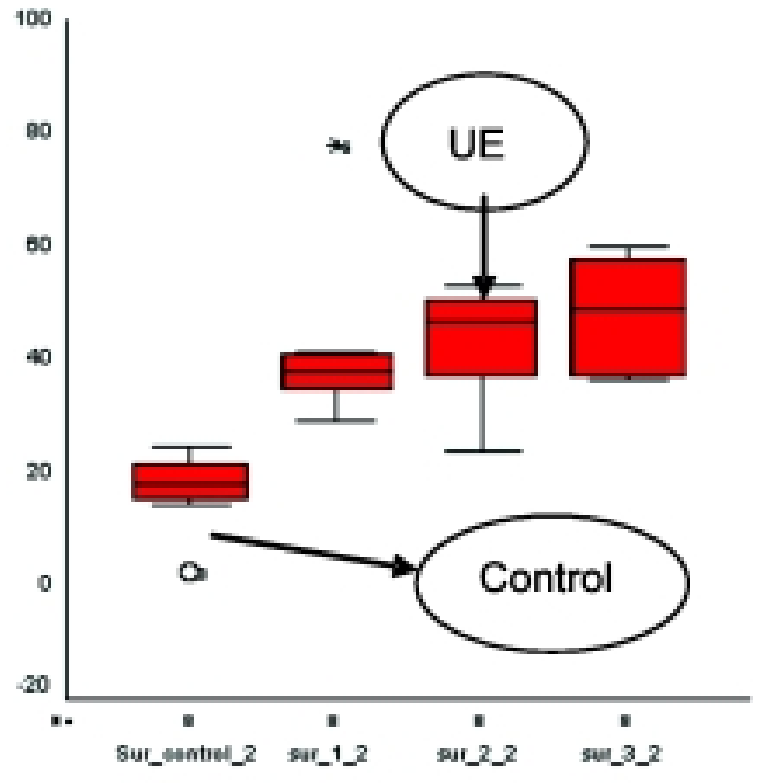

Figura 1. Análisis estadístico para nitratos post-tratamiento con el consorcio bacteriano aislado.

La actividad desnitrificante (AD) del consorcio bacteriano, fue demostrada mediante análisis fisicoquímicos observando mediante espectrofotometría, una disminución significativa de nitratos en las Unidades experimentales ( $\mathrm{p} £$ 0.05) en relación al control después de introducir el consorcio bacteriano, figura 1.

\section{Discusión}

El consorcio bacteriano identificado a partir del suelo problema estuvo compuesto por: Bacillus megaterium, Bacillus licheniformis, Pseudomonas sp, Acinetobacter sp, Propionibacterium, Clostridium sp, Actinomyces. Peptoestreptococcus, Sthaphylococcus coagulasa negativa, Corynebacterium.

El recuento promedio de UFC/g de suelo post-tratamiento fue de $6.3 \times 10^{4} \mathrm{y}$ en el surco control fue de $2,6 \times 10^{4}$. Utilizando todo el consorcio no se pudo determinar una concentración bacteriana óptima para la desnitrificación; por lo que se sugiere en futuros ensayos probar diferentes asociaciones bacterianas y diferentes concentraciones de las mismas. En cuanto al análisis de los nitratos se observaron diferencias significativas entre las unidades experimentales y el control, mostrando que el consorcio bacteriano aislado llevó a cabo el proceso de desnitrificación de una manera efectiva.
Numerosos estudios han reportado microorganismos como potentes desnitrificantes en suelo $(3,5,6)$. Sin embargo, no existen reportes de trabajos utilizando consorcios bacterianos. En este trabajo se realizó la biorremediación con un consorcio nativo de bacterias desnitrificantes, lo que permite combinar y complementar las funciones metabólicas de diferentes microorganismos, para que colectivamente desnitrifiquen el suelo. Adicionalmente al estar en grupo las diferentes especies bacterianas pueden tolerar los cambios físico-químicos que se den en el ambiente durante el proceso de biorremediación $(3,6,7,8)$.

En la presente investigación se aisló Pseudomonas stutzeri, la cual se encuentra ampliamente distribuida en la suelos y agua, y ha sido recuperada de humus, estiércol, paja, aguas servidas, aguas estancadas, alimentos preparados para bebes, equipos hospitalarios, cosméticos para los ojos, y diversos materiales clínicos. Esta especie ha sido reportada frecuentemente como desnitrificante del suelo (9).

También se aislaron diferentes microorganismos de la familia Bacillaceae, sus numerosas especies suelen ser mesófilas, aerobias o anaerobias facultativas, algunas de sus especies termófilas pueden desarrollarse también en los extremos de acidez y alcalinidad con $\mathrm{pH}$ entre 2-10, por lo que pueden recuperarse a partir de una variedad de nichos ecológicos. Las diferentes especies de Bacillus son de amplia distribución, habitan suelos, agua y polvo ambiental. El género Bacillus, ha sido informado como desnitrificantes fuertes y rápidos, ya que convierten los nitratos a nitritos en 24 horas como es el caso de la especie Bacillus licheniformis (8).

Otro de los géneros, pertenecientes a la familia Bacillaceae, el Clostridium, con especies anaerobias facultativos ó estrictas, comúnmente encontradas en suelo también han sido informados como potentes biorremediadores, utilizados con frecuencia para degradación de derivados de petróleo (10).

En este trabajo se encontraron, haciendo parte del consorcio nativo, especies de Staphylococcus coagulasa negativa, las cuales están ampliamente distribuidas en 
diferentes nichos ecológicos y se caracterizan por su gran capacidad de tolerancia al medio ambiente (8).

También se encontraron especies de: Propionibacterium, que son bacilos Gram positivos, anaerobios facultativos, frecuentemente aislados de suelos, los cuales también utilizan el $\mathrm{NO}_{3}^{-}$como aceptor de electrones; de Peptostreptococcus, cocos Gram positivos, de crecimiento lento en medios convencionales, no hemolíticos, distribuidos en el medio ambiente.

Otro género encontrado fue Corynebacterium, bacilos aerobios, Gram positivos, formadores de gránulos metacromáticos, sus diferentes especies han sido reportadas con frecuencia aisladas de diferentes tipos de suelo $(6,11)$. El Acinetobacter un bacilo Gram negativo, no fermentador de glucosa, distribuido ampliamente en el medio ambiente, en diferentes tipos de suelo y agua ha sido reportado como especie capaz de desnitrificar de manera lenta y débil (12), también fue identificado en este estudio haciendo parte del consorcio nativo.

Finalmente, otro de los microorganismos encontrados fue el género Actinomyces, bacilos filamentosos y ramificados, pleomorficos, Gram variables, de crecimiento típico en placas de agar, que también ha sido reportado en la literatura como microorganismo desnitrificante (12).

Debido a que algunas especies comúnmente identificadas por PCR no fueron aisladas en nuestro estudio, se recomienda en futuros estudios utilizar técnicas de biología molecular para la identificación de microorganismos difíciles de recuperar por cultivo en placa o en medio líquido que aparecen en la literatura identificados y haciendo parte de la población nativa de suelos contaminados (13).

\section{Agradecimientos}

Los autores agradecen a la Universidad de la Salle y a la Universidad Colegio Mayor de Cundinamarca por la financiación de la investigación, al Sr. Guillermo López, propietario de la Finca Siempre Viva, y al Dr. Ricardo Montealegre Coordinador de Laboratorios Universidad de la Salle por su apoyo incondicional.

\section{Referencias}

1. Çelen E, Akif M. Isolation and characterization of aerobic denitrifiers from agricultural soil. Turk Journal Biology 2003; 29: $9-14$.

2. Eweis J, Schroeder, E., Chang, D., Scow, K., Morton, R., and Caballero, R. Principios de Biorecuperación. Tratamientos para la descontaminación y regeneración de suelos y aguas subterráneas mediante procesos biológicos y fisicoquímicos. McGraw Hill. España. 1999. p. 131-147.

3. Rich J,Heichen P, Bottomley J, Cromack J. Community Composition and Functioning of Denitrifying Bacteria from Adjacent Meadow and Forest Soils. Applied and Environmental Microbiology. 2003;69(10): 5974-82.

4. Rösh C, Mergel A, Bothe H. Biodiversity of denitrifying and dinitrogen-fixing bacteria in an acid forest soil. Appl and Environmental Microbiol. 2002;3818-29.

5. Harting, E., and W. G. Zumft. Kinetics of nirS expression (cytochrome cd1 nitrite reductase) in Pseudomonas stutzeri during the transition from aerobic respiration to denitrification: evidence for a denitrification-specific nitrateand nitrite-responsive regulatory system. J. Bacteriol 2002; 181:161-166.

6. Sachiko Y, Naohiro N, Satoshi T, Akira H, Yubei H. Aerobic Denitrifyng Bacteria That Produce Low Levels of Nitrous Oxide. Applied and Enviromental Microbiology 2004;69(6):3152-3157.

7. Naoki T, Bernard M, Sakairi C, Sakaguchi Y, Kato I, Zhemin Z, Shoun H. Aerobic Denitrifying Bacteria That Produce Low Levels of Nitrous Oxide. Applied and Environmental Microbiology. 2003;69(6): 3152-57.

8. Kim H, Vanparys B, Wittebolle L, Verstraete W, Boon N, De Vos P. Cultivation of Denitrifying Bacteria: Optimization of isolation Conditions and Diversity Study. Applied an Enviromental Microbiology.2006.72(4)2637-2643.

9. Koneman EW. Diagnóstico microbiológico: texto y atlas color. 5 th ed Buenos Aires; 2001

11. Denariaz G, Dayne W, Gall J. A halophilic denitrifier. Bacillus halophilic denitrifier sp. J.Syst.Bacteriol; 1989:39:145-151.

12. Sawer C. Chemestry For Enviromental Engineering. 1978.Mc.Graw-Hill.534p.

13. Braker W, Feseldt A, Witzel K. Develoment of PCR primer system amplification of nitrite reductase genes (NirK and nirS) to detect denitrifyng bacteria in environmental samples. Appl and Environ Microbiol. 1998; 3769-75. 